\title{
Product Development and International Trade
}

\section{Citation}

Grossman, Gene M., and Elhanan Helpman. 1989. Product development and international trade. Journal of Political Economy 97(6): 1261-1283.

\section{Published Version}

doi:10.1086/261653

\section{Permanent link}

http://nrs.harvard.edu/urn-3:HUL.InstRepos:3445094

\section{Terms of Use}

This article was downloaded from Harvard University's DASH repository, and is made available under the terms and conditions applicable to Other Posted Material, as set forth at http:// nrs.harvard.edu/urn-3:HUL.InstRepos:dash.current.terms-of-use\#LAA

\section{Share Your Story}

The Harvard community has made this article openly available.

Please share how this access benefits you. Submit a story.

Accessibility 


\section{CHICAgo journals}

Product Development and International Trade

Author(s): Gene M. Grossman and Elhanan Helpman

Source: The Journal of Political Economy, Vol. 97, No. 6 (Dec., 1989), pp. 1261-1283

Published by: The University of Chicago Press

Stable URL: http://www.jstor.org/stable/1833238

Accessed: $1 1 \longdiv { / 1 2 / 2 0 0 9 \text { 16:10 } }$

Your use of the JSTOR archive indicates your acceptance of JSTOR's Terms and Conditions of Use, available at http://www.jstor.org/page/info/about/policies/terms.jsp. JSTOR's Terms and Conditions of Use provides, in part, that unless you have obtained prior permission, you may not download an entire issue of a journal or multiple copies of articles, and you may use content in the JSTOR archive only for your personal, non-commercial use.

Please contact the publisher regarding any further use of this work. Publisher contact information may be obtained at http://www.jstor.org/action/showPublisher?publisherCode=ucpress.

Each copy of any part of a JSTOR transmission must contain the same copyright notice that appears on the screen or printed page of such transmission.

JSTOR is a not-for-profit service that helps scholars, researchers, and students discover, use, and build upon a wide range of content in a trusted digital archive. We use information technology and tools to increase productivity and facilitate new forms of scholarship. For more information about JSTOR, please contact support@jstor.org.

The University of Chicago Press is collaborating with JSTOR to digitize, preserve and extend access to The Journal of Political Economy. 


\title{
Product Development and International Trade
}

\section{Gene M. Grossman}

Princeton University

\section{Elhanan Helpman}

Tel Aviv University

\begin{abstract}
We develop a multicountry, dynamic general equilibrium model of product innovation and international trade to study the creation of comparative advantage through research and development and the evolution of world trade over time. In our model, firms must incur resource costs to introduce new products, and forward-looking potential producers conduct R \& D and enter the product market whenever profit opportunities exist. Trade has both intraindustry and interindustry components, and the different incentives that face agents in different countries for investment and savings decisions give rise to intertemporal trade. We derive results on the dynamics of trade patterns and trade volume and on the temporal emergence of multinational corporations.
\end{abstract}

\section{Introduction}

International economists have long used static models of comparative advantage and (more recently) scale economies to great advantage in studying the pattern of international trade and the normative properties of trading equilibria. But increasingly, issues of concern to theorists and casual observers alike are inherently dynamic in nature.

Grossman's research was supported by the Alfred P. Sloan Foundation and the National Science Foundation under grant SES-8606336. Helpman's research was supported by the Bank of Sweden Tercentenary Foundation. He thanks the Department of Economics at the Massachusetts Institute of Technology for providing a hospitable research environment. We are grateful to Itzhak Zilcha for helpful discussions and to Avinash Dixit and Carl Shapiro for comments on an earlier draft. 
Attention has focused recently on the creation of comparative advantage by technological innovation, the relationship between trade policy and economic growth, and the dynamic evolution of the volume and pattern of world trade. The static analysis of international trade must be extended if we are to deal with these new concerns.

In this paper, we develop a multicountry, dynamic, general equilibrium model of product innovation and international trade to study the creation of comparative advantage through research and development (R \& D) and the evolution of world trade over time. We build on the static analyses of trade in differentiated products by Krugman (1979a, 1981), Dixit and Norman (1980), and Feenstra and Judd (1982), and also on Judd's (1985) investigation of product development in a closed economy.

In our model, firms incur resource costs to introduce new products. Forward-looking potential producers conduct R \& D and enter the product market whenever profit opportunities exist. New products substitute imperfectly for old, and prices, interest rates, and the pattern of trade evolve over time as more commodities become available for purchase. Trade has both intraindustry and interindustry components, with the former governed by $\mathrm{R} \& \mathrm{D}$ expenditures and the latter by resource endowments. International capital flows take place to finance $\mathrm{R} \& \mathrm{D}$, and in some circumstances multinational corporations may emerge.

The approach adopted here differs in important respects from several recent studies of the dynamics of trade with product innovation, such as Krugman (1979b), Dollar (1986), Jensen and Thursby (1987), and Segerstrom, Anant, and Dinopoulos (1987). These papers have provided useful insights into the steady-state properties of trading equilibria when products are initially developed in the North and later imitated by the South. But all except perhaps the last have been incomplete in important ways, because of a failure to incorporate all general equilibrium interactions, the lack of consideration of the economic factors that drive the rate of product innovation, or other features. ${ }^{1}$ Our framework is distinguished by its explicit treat-

\footnotetext{
${ }^{1}$ More specifically, Krugman posits exogenous rates of product innovation and imitation to study the determinants of steady-state wages and welfare in a one-sector model of the product cycle. Dollar improves on Krugman's work by allowing the rate of imitation to depend on manufacturing cost differentials. His relationship is essentially ad hoc, and he maintains Krugman's assumption that the rate of product innovation is exogenous. These authors do not consider the resource costs of innovation and imitation, nor do they allow for intertemporal profitability considerations. Jensen and Thursby do allow $\mathrm{R} \& \mathrm{D}$ to be determined by intertemporal profit maximization, but they assume that there is a single, monopolistic developer and that the interest rate is exogenous and constant. None of these studies, or any other with which we are familiar, devotes much attention to the evolution of the pattern of trade along the path to a steady state, which is our primary concern here.
} 
ment of both the private incentive for investment in R \& D and the resource requirements of this activity.

In order to focus sharply on the dynamics of product development and the creation of comparative advantage by $R \& D$, in this study we abstract from all forms of factor accumulation. This abstraction helps us to bring out the novel features introduced by endogenous innovation and renders the exercise more tractable. Future research might gainfully consider the interaction between the evolution of the pattern of trade that is dictated by technological progress and the more familiar dynamics emanating from resource expansion.

The organization of the paper and some of the major results are as follows. In Section II, we develop the model and derive the world equilibrium that would result in the absence of any international borders. Section III presents our investigation of the pattern of trade in a two-country, two-factor world, with the factors interpreted to be unskilled labor and human capital. If both R \& D and the production of differentiated goods are more human capital-intensive activities than the production of a traditional good and if all activities bear Leontief production technologies, then the human capital-rich country will be a net exporter of differentiated products and an importer of the traditional good at every moment in time. This is true despite the fact that the human capital-rich country initially devotes more of its resources to R \& D (as opposed to production) and despite the fact that trade is not balanced along the equilibrium path. The model predicts a rising share of trade in world gross national product (GNP), at least when $\mathrm{R} \& \mathrm{D}$ is the most human capital intensive of the three activities. Concerning intertemporal trade, we show that the human capitalrich country has both a greater incentive to invest and a greater incentive to save (per capita), the latter because of its declining relative factor income. Consequently, it appears that this country may run either a surplus or a deficit on current account in the dynamic equilibrium.

In Section IV, we introduce the possibility of multinational corporations in the manner of Helpman (1984). We assume that headquarter services can be separated geographically from production activities and that only the former must take place in the country in which a differentiated product has been developed. If headquarter services are more human capital intensive than production, then the possibility of multinational activity expands the set of distributions of the world's factor endowment for which international exchange can reproduce the integrated world equilibrium. For certain compositions of factor endowments, we predict that multinational enterprises will emerge at a particular point in time and remain active ever after. The extent of multinationality, as measured by output, employment of 
subsidiaries, or the number of multinational firms, expands over time, at least initially and as the world economy approaches the steady state.

\section{A Dynamic Model of R \& D}

We consider a world economy with three activities: the production of a "traditional" commodity under competitive conditions, the production of a continuum of varieties of a "modern" industrial product, and research and development that leads to the acquisition of the knowhow needed to produce new brands of the industrial good. Our modern goods are horizontally differentiated, so that newly invented products do not displace older varieties. We leave for future research the issue of trade dynamics in a world of vertically differentiated products, in which products become obsolete after a time. ${ }^{2}$

At every point in time there exists a given (measure of the) number of varieties that were developed in the past. Producers of these varieties engage in oligopolistic competition by setting prices. Given demands and costs, this process determines prices, outputs, and current operating profits. An entrepreneur who contemplates developing a new brand can calculate the future stream of potential operating profits. He or she chooses to develop the brand only if the present value of this stream is at least as large as the cost of $R \& D$. The competitive entry process leads to aggregate investment in $\mathrm{R} \& \mathrm{D}$ such that a brand's development cost is just equal to the present value of its future profits (unless no further products are developed).

As in Helpman and Krugman (1985), it proves convenient to solve for the "integrated world equilibrium," that is, the equilibrium that would obtain in the absence of any international borders. Under conditions that give rise to factor price equalization, a world trading equilibrium reproduces the integrated equilibrium in its essential details. So properties of the latter equilibrium can be applied to the analysis of the former. For this reason the following discussion deals first with the integrated economy.

\section{A. Consumers}

Infinitely lived consumers maximize total lifetime utility. The representative consumer has a time-separable intertemporal utility func-

\footnotetext{
${ }^{2}$ The model studied by Segerstrom et al. (1987) does have the feature that improved products cause older variants to disappear, but the analysis focuses only on the steadystate properties of the equilibrium.
} 
tion

$$
U=\int_{0}^{x} e^{-\rho t} \log u(\cdot) d t
$$

where $\rho$ is the constant subjective discount rate and $u(\cdot)$ is an instantaneous subutility function. We adopt a particular form for $u(\cdot)$,

$$
u=\left[\int_{0}^{n} c_{x}(i)^{\alpha} d i\right]^{s_{x} / \alpha} c_{y}^{1-s_{x}}, \quad \alpha, s_{x} \in(0,1),
$$

where $c_{x}(i)$ is consumption of differentiated product $i, c_{y}$ is consumption of the traditional good, and $n$ is the (measure of the) number of available varieties. We note that this form implies constant expenditure shares $s_{x}$ and $1-s_{x}$ on commodity classes $x$ and $y$, and a constant elasticity of substitution between any two differentiated products of $\sigma=1 /(1-\alpha)>1$.

The consumer's maximization problem can be solved in two stages. First we find $\left\{c_{x}(i)\right\}$ and $c_{y}$ to maximize $u(\cdot)$ given total expenditure at time $t, E(t)$, prices, and the available brands. Then we solve for the time pattern of expenditures that maximizes $U$. The solution to the first stage gives instantaneous demand functions ${ }^{3}$

$$
c_{x}(i)=s_{x} E \frac{p(i)^{-\sigma}}{\int_{0}^{n(t)} p(j)^{1-\sigma} d j}
$$

and $c_{y}=\left(1-s_{x}\right) E / p_{y}$, where $p(i)$ is the price of differentiated product $i$ and $p_{y}$ is the price of the traditional good.

In maximizing $U$, the consumer must satisfy an intertemporal budget constraint. We assume that the consumer can borrow or lend freely on a capital market with instantaneous rate of interest $\dot{R}(\tau)$. The budget constraint is

$$
\int_{t}^{\infty} e^{-|R(\tau)-R(t)|} E(\tau) d \tau=\int_{t}^{\infty} e^{-|R(\tau)-R(t)|} I(\tau) d \tau+A(t),
$$

where $I(\tau)$ is the consumer's factor income in period $\tau, A(t)$ is the value of his accumulated assets at $t$, with $A(0)=0$, and $R(\tau)$ is the cumulative interest factor through time $\tau$. Then if we substitute (3) into (2) and the result into (1), the first-order condition for maximizing $U$ subject to (4) at $t=0$ implies ${ }^{4}$

$$
\frac{\dot{E}}{E}=\dot{R}-\rho \text {. }
$$

\footnotetext{
${ }^{3}$ See Helpman and Krugman (1985, chap. 6) for more details.

${ }^{1}$ This can be seen as follows. The indirect utility function derived from (2) has the form $v[p(t), E(t)]=E(t) f(p(t))$. Then $\log u(\cdot)=\log E(t)+\log f(p(t))$, and the first-order condition for maximization of (1) implies $e^{\cdot \rho t} / E(t)=\zeta e^{-R(t)}$, where $\zeta$ is the timeindependent Lagrange multiplier associated with the budget constraint in (4).
} 


\section{B. Producers}

Costs of manufacturing industrial products comprise two parts, fixed development costs and variable production costs. Production takes place under constant returns to scale, and the input requirements for $\mathrm{R} \& \mathrm{D}$ do not vary with the number of innovating firms. Let $\phi_{x}\left(\mathbf{w}_{f}\right)$ be the unit cost in production and $\phi_{n}\left(\mathbf{w}_{f}\right)$ the cost of developing a brand, where $\mathbf{w}_{f}$ is a vector of input prices. ${ }^{5}$ These costs are the same for all brands, regardless of whether or not the variety has previously been introduced by another entrepreneur. Then $\phi_{n}(\cdot)$ is the fixed cost and $\phi_{x}(\cdot)$ is the average and marginal variable cost for all firms in this sector.

The number of potential products is infinite. Therefore, it will never be rational for an entrepreneur to develop an already existing brand, and each innovator enjoys monopoly power in the production of his particular variety for the indefinite future.

A producer of an existing brand faces at time $t$ a measure $n(t)$ of competitors who have developed products in the past. He takes as given the aggregate expenditure level $E(t)$ and the pricing policy of the competitors and sets the price of his brand so as to maximize operating profits, namely, revenue minus production costs, using the demand function given in (3). As is well known, this results in fixedmarkup pricing over unit production costs. Since all producers are similar, we consider the symmetric equilibrium. In this equilibrium, output per variety $x(i)=x$ and prices $p(i)=p$ for all $i \in[0, n(t)]$ satisfy

$$
x=s_{x} \frac{E}{p n}
$$

and

$$
\alpha p=\phi_{x}\left(\mathbf{w}_{f}\right) .
$$

The resulting operating profits per variety are

$$
\pi=(1-\alpha) s_{x} \frac{E}{n} .
$$

An entrepreneur has perfect foresight regarding the evolution of spending $E$ and the number of firms $n$. Therefore, using (8), he has perfect foresight regarding profits per variety. In an equilibrium the present value of these profits cannot exceed current R \& D costs. Hence, if at time $t$ there is positive but finite investment in product

\footnotetext{
${ }^{5}$ An implicit assumption here is that product development does not require finite time. We could relax this assumption without substantially affecting the structure of the model.
} 
development, each new variety breaks even, that is,

$$
\int_{t}^{\infty} e^{-[R(\tau)-R(t)]} \pi(\tau) d \tau=\phi_{n}\left[\mathbf{w}_{f}(t)\right] .
$$

We normalize nominal prices so that

$$
1=\phi_{n}\left[\mathbf{w}_{f}(t)\right] \text { for all } t .
$$

With this choice of numeraire, (9) implies that the instantaneous interest rate is equal to the flow of operating profits, that is,

$$
\pi(t)=\dot{R}(t)
$$

The traditional good also is produced subject to constant returns to scale. Its unit cost function is $\phi_{y}\left(\mathbf{w}_{f}\right)$. Its price, which equals marginal cost, satisfies

$$
p_{y}=\phi_{y}\left(\mathbf{w}_{f}\right) \text {. }
$$

Equations (7), (10), and (12) describe the equilibrium relationships between product and factor prices.

\section{Integrated Equilibrium}

First, substitute (8) and (11) into (5) to obtain

$$
\frac{\dot{E}}{E}=(1-\alpha) s_{x} \frac{E}{n}-\rho .
$$

This is the first differential equation that will be used to describe the evolution of the integrated economy over time. It shows the rate of change of spending as a function of spending and the number of available varieties. The next step is to derive a differential equation for changes in the number of available brands, that is, an investment equation.

Let $\mathbf{a}_{z}\left(\mathbf{w}_{f}\right)$ be the (column vector) gradient of the unit cost function $\phi_{z}\left(\mathbf{w}_{f}\right), z=n, x, y$. Then $\mathbf{a}_{z}\left(\mathbf{w}_{f}\right)$ represents the employment vector per unit output at factor prices $\mathbf{w}_{f}$, and the factor market-clearing conditions are

$$
\mathbf{a}_{n}\left(\mathbf{w}_{f}\right) \dot{n}+\mathbf{a}_{x}\left(\mathbf{w}_{f}\right) X+\mathbf{a}_{y}\left(\mathbf{w}_{f}\right) Y=\mathbf{V}
$$

where

$$
X=n x
$$

is the aggregate output of industrial products, $Y$ is output of the traditional goods, and $\mathbf{V}$ is the vector of available inputs. Using (7), (10), (12), and (14), together with the goods market-clearing condi- 
tions

$$
s_{x} \frac{E}{p}=X
$$

and

$$
\left(1-s_{x}\right) \frac{E}{p_{y}}=Y,
$$

we can solve for equilibrium commodity and factor prices and sectoral output levels all as a function of the level of spending, $E$. We denote these functional relationships by $\mathbf{w}_{f}(E), p(E), p_{y}(E), X(E), Y(E)$, and

$$
\dot{n}=v(E) \text {. }
$$

Equations (13) and (18) constitute an autonomous system of differential equations. They apply whenever the implied rate of product development is nonnegative. Global stability requires the function $v(\cdot)$ to be declining in $E$ whenever $v(E)>0$. For now, we simply assume that this condition is satisfied. ${ }^{\circ}$

The phase diagram for the system is depicted in figure 1. From

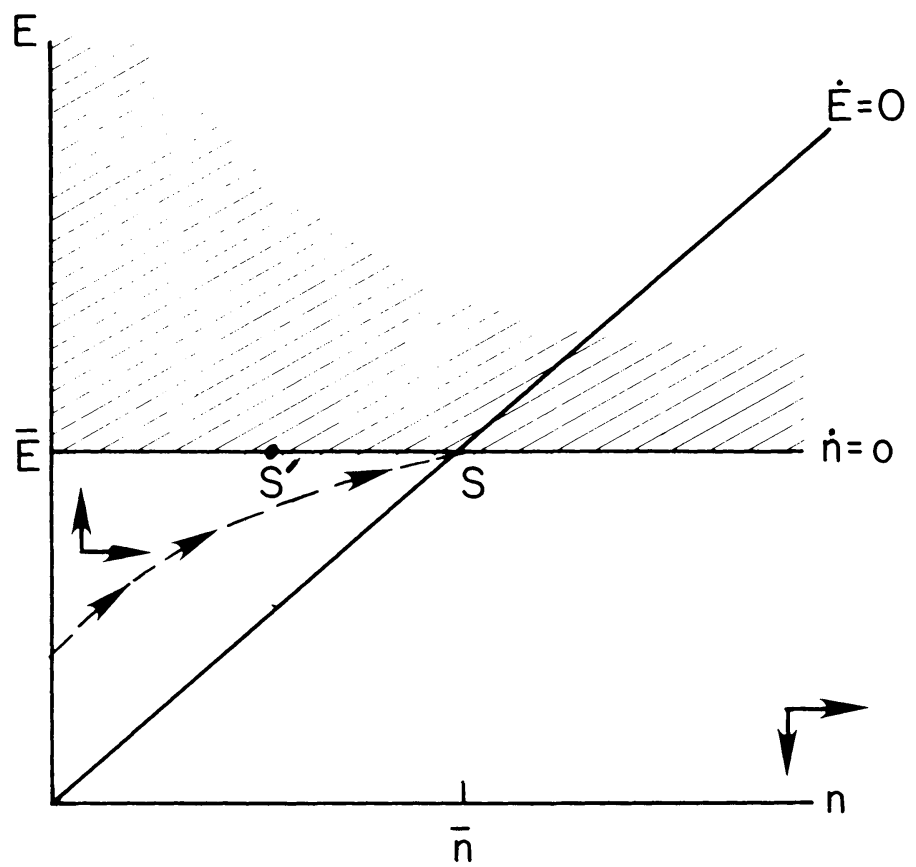

FIG. 1

${ }^{6}$ For the special case that we consider in the next subsection, we establish that the stability condition is always satisfied. 
(13), we see that the $\dot{E}=0$ schedule is an upward-sloping line in $(E, n)$ space with slope given by $\rho /(1-\alpha) s_{x}$. Equation (18) implies that $\dot{n}=0$ for some particular value of $E$, which we denote by $\bar{E}$. The horizontal line in the figure depicts points at which there is no product development. Note that there can be no equilibrium of the economy above this line because this would require negative product development, which of course is not feasible. ${ }^{7}$ The relevant regions in the figure are those on or below the horizontal line.

Point $S$ in the figure represents the steady state. For $n(0)<\bar{n}$, there is a single trajectory that leads to point $S$, represented by the dashed path. This is, in fact, the unique equilibrium trajectory for $n(0)<\bar{n}$. For initial points below this trajectory, expenditure approaches zero as time progresses, which violates the conditions for consumer optimization. For initial points above the path, the conditions for profit maximization ultimately are violated. To see this, note that any such trajectory hits the horizontal line along which $\dot{n}=0$ at a point such as $S^{\prime}$ to the left of $S$. With $E=\bar{E}$, it remains there ever after. But the constancy of expenditure implies, from (5), that $\dot{R}=\rho$. Since $S^{\prime}$ is above the upward-sloping ray, operating profits $\pi=(1-\alpha) s_{x} \bar{E} / n$ are larger than $\rho$ and hence the interest rate. This means that the present value of operating profits exceeds the cost of $R \& D$, making it profitable to develop new products at $S^{\prime}$. Therefore, trajectories that hit the horizontal line to the left of $S$ are not consistent with long-run equilibrium. 8

\section{Special Case}

We now consider a special case that will be used to discuss trade issues. There are only two factors of production-unskilled and skilled labor-and there are fixed input-output coefficients. ${ }^{9}$ Hence,

$$
\mathbf{V}=\left[\begin{array}{l}
L \\
H
\end{array}\right], \mathbf{w}_{f}=\left[\begin{array}{l}
w \\
r
\end{array}\right], \mathbf{a}_{z}\left(\mathbf{w}_{f}\right)=\left[\begin{array}{l}
a_{I, z} \\
a_{H z}
\end{array}\right] \text { for } z=n, x, y,
$$

${ }^{7}$ Suppose that $\dot{n}=0$, and consider the system of equilibrium conditions comprising (7), (10), (12), (14), (16), and (17). These are $5+k$ equations in $5+k$ unknowns, where $k$ is the number of factors of production. The unknowns in this system are the $k$ factor rewards, two prices for final consumer goods, two aggregate output levels for the finalgoods sectors, and the expenditure level. Naturally, the solution for the expenditure level in this system is $\bar{E}$. Thus $\dot{n}=0$ in equilibrium implies $E=\bar{E}$, and the system can be only on or below the horizontal line in the figure.

${ }^{8}$ If the initial number of products exceeds $\bar{n}$, the economy settles immediately at a stationary state, with the number of varieties and all real magnitudes forever constant. In what follows, attention is focused on the case in which the initial number of products is smaller than $\bar{n}$.

${ }^{9}$ While our approach remains valid for more general production functions than the 
where $L$ stands for unskilled labor and $H$ stands for human capital, which is our measure of skilled labor. We assume that the traditional sector is the least human capital intensive and that the overall human capital to labor ratio satisfies $a_{H y} / a_{I-y}<H / L<a_{H j} / a_{L j}$ for $j=x, n$. The latter assumption is needed to ensure full employment.

The comparative statics analysis of (7), (10), (12), (14), (16), and (17) that is executed in the Appendix shows that the function $v(E)$ is declining for this case. Therefore, the dynamic path is as described in figure 1; the number of available brands and expenditure are increasing over time. This in turn implies that the level of $R \& D$ activity is declining through time, as well as the following price and quantity dynamics (see the Appendix for a proof). ${ }^{10}$

Proposition 1. (a) $\dot{w} / w>\dot{p}_{y} / p_{y}>\dot{p} / p>\dot{r} / r ;(b) \dot{p}_{y}>0 ;(c) \dot{r}<0 ;(d) \dot{p}$ $>0$ if and only if $a_{H n} / a_{L n}>a_{H x} / a_{L-x} ;(e) \partial \dot{n} / \partial t<0 ;(f) \dot{X}>0 ;(g) \dot{Y}<0$ if and only if $a_{H n} / a_{L, n}>a_{H x} / a_{L x}$; and $(h) \dot{E}>0$.

We see that the real wage (of unskilled labor) is rising and the real reward to human capital is falling through time. This statement refers, however, only to the standard method of measuring real incomes. Since in this type of an environment variety is valued per se (see Helpman and Krugman 1985, chap. 6) and the available variety increases over time, real incomes of unskilled workers necessarily increase but real incomes of skilled workers need not decline. ${ }^{11}$ The

Leontief technology, the dynamics that result are considerably more complicated than here. We have so far been unable to derive interesting results about trade dynamics for the general case.

${ }^{10}$ In deriving our comparative statics results, we have assumed that full employment of both factors obtains all along the equilibrium trajectory. As is well known, even in static models, full employment is not guaranteed for fixed-coefficient production functions. In the steady state of our dynamic system we have an essentially static two-sector model (because R \& D is zero) with a piecewise-linear, kinked transformation curve. Full employment then requires restrictions on the parameters of the utility function so that the slope of the indifference curve at the kink, adjusted for the degree of monopoly power $1 / \alpha$, falls between the slopes of the flat portions of the transformation curve. Put differently, full employment obtains in the steady state if, for $E=\bar{E}$, the solution to the system of equations (7), (10), (12), (14), (16), (17), and (18) yields nonnegative factor rewards. We also require nonnegative values of the factor rewards when the system is solved with $E=E(0)$. These two conditions at the endpoints ensure full employment and nonnegative factor rewards along the entire equilibrium trajectory since the wage rate is rising and the reward to human capital is falling whenever there is full employment (see parts $a, b$, and $c$ of proposition 1). If these conditions are not met, however, there may be unemployment of unskilled labor during an initial phase of the dynamic equilibrium, unemployment of human capital during an ultimate stage, or both.

${ }_{11}$ The temporal indirect utility function of a representative agent is calculated to be

$$
\text { constant }+s_{x}\left(\alpha^{-1}-1\right) \log n+\log I-\left[s_{x} \log p+\left(1-s_{x}\right) \log p_{y}\right],
$$

where $I$ is his income. The last two terms represent the usual real income component, where the last term represents the deflator. It is clear from part $a$ of proposition $\mathbf{l}$ that this real income component is rising for unskilled workers and falling for skilled workers. However, apart from this component, there exists the term with $n$, which repre- 
product development sector contracts while the production of industrial goods expands. The decline in $\mathrm{R} \& \mathrm{D}$ can be understood intuitively as follows. At least in the neighborhood of the steady state, demand for each individual variety and hence profitability in the industrial sector decline over time (see Sec. IV). As the profit rate falls, the (real) interest rate must fall as well if entrepreneurs are to be willing to invest in innovation. But as long as the interest rate remains above the discount rate, spending is rising, and resources must be released from the $\mathrm{R} \& \mathrm{D}$ sector to satisfy the increased consumer demand. The process stops when the profit rate has fallen to the level of the discount rate, at which time spending ceases to grow, but then consumers spend all their income and no savings exist to finance further innovation.

\section{The Pattern of Trade in a Two-Country World}

We suppose now that the world consists of two countries, labeled $\mathrm{A}$ and $\mathrm{B}$. The two countries share common tastes and technologies identical to those specified for the integrated economy. We allow for the existence of integrated world commodity and financial markets but assume that factor services and "blueprints" are not tradable. In this section we assume as well that an entrepreneur cannot establish production facilities offshore; we relax this assumption in the next section to allow for the emergence of multinational corporations. We ask first whether, with trade, the world equilibrium replicates that of the integrated economy, as described in Section II $D$. In other words, we consider the conditions under which factor price equalization characterizes the trade equilibrium. Then, for those cross-country divisions of $H$ and $L$ that indeed are consistent with factor price equalization everywhere along the equilibrium path, we describe the evolution of world trade.

Consider figure 2. The dimensions of the rectangle in the figure represent worldwide factor endowments, with the division of these endowments between countries represented by a point such as $E$ in the interior of the rectangle. For concreteness, we suppose that country $\mathrm{A}$ is the relatively human capital-rich country, that is, $H_{a} / L_{a}>$ $H_{b} / L_{b}$.

At time $t=0$, the resource allocation of the integrated equilibrium is found by substituting $E(0)$ and $n(0)=0$ from the equilibrium trajectory into (7), (10), (12), (14), (16), (17), and (18) and solving for

sents the love-of-variety effect. This real income component is rising as a result of expanding variety. 


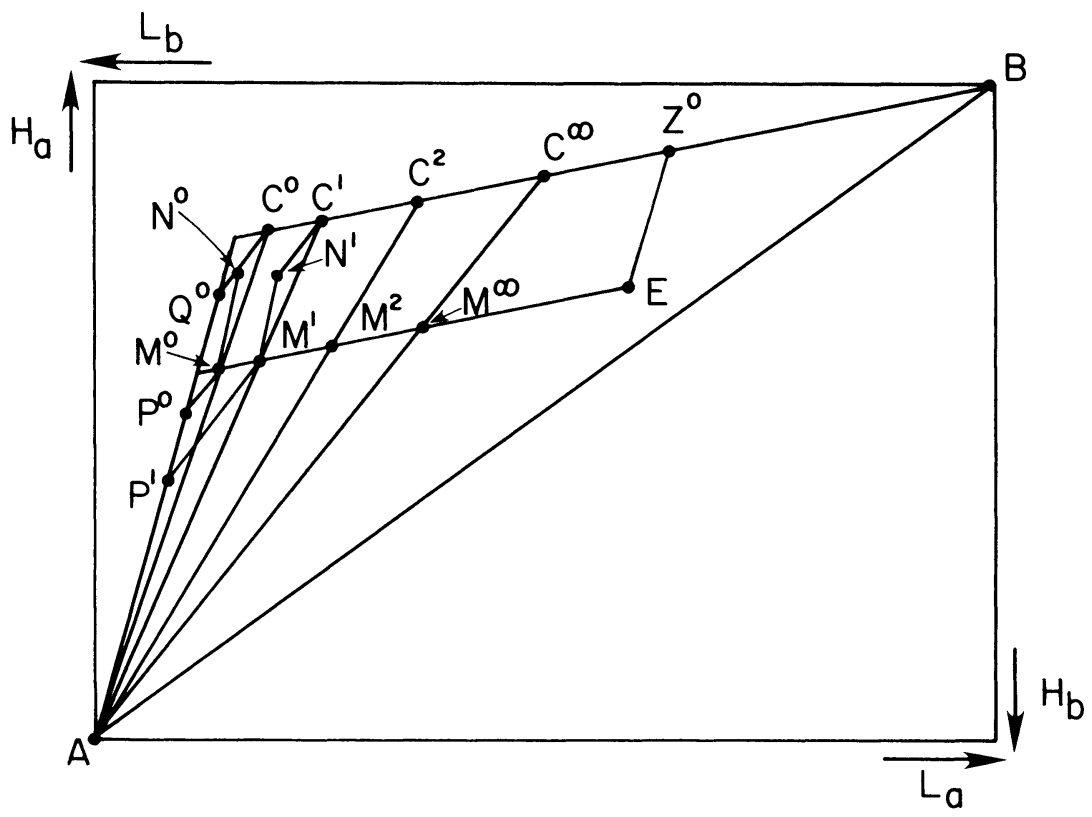

FIG. 2

$\dot{n}(0), X(0)$, and $Y(0) .{ }^{12}$ Let points $Q^{0}$ and $C^{0}$ in the figure represent this allocation, where vector $A Q^{0}$ is employed in $\mathrm{R} \& \mathrm{D}, Q^{0} C^{0}$ is employed in the modern sector, and $C^{0} B$ is employed in the traditional sector (and the slopes of these vectors correspond to the factor proportions required in each of these activities). The allocation of the integrated equilibrium can be achieved in a two-country world as long as it is possible to decompose the industry employment vectors into nonnegative components for each country that exhaust their separate endowments. In the figure, this is accomplished with employment vectors $A M^{0}\left(=A P^{0}+P^{0} M^{0}\right)$ and $M^{0} E$ in country A and vectors $E Z^{0}$ $\left(=M^{0} N^{0}+N^{0} C^{0}\right)$ and $Z^{0} B$ in country B. Evidently, the feasibility of such a decomposition requires that point $E$ be in the interior of the triangle $A C^{0} B$. A sufficient condition for this is $a_{H n} / a_{L n}>H_{a} / L_{a}>$ $H_{b} / L_{b}>a_{H y} / a_{L . y}$.

In the steady state, $\mathrm{R} \& \mathrm{D}$ ceases, and all resources are devoted to production. Let point $C^{\infty}$ represent the allocation of resources to the

\footnotetext{
12 The system of equations that determines resource allocations, commodity prices, and factor rewards yields a solution for $X(0)$ that is strictly positive when $E=E(0)$, despite the fact that $n(0)=0$. Strictly positive consumption of both classes of goods is dictated by the Cobb-Douglas form of the subutility function. It requires, of course, that $x(t) \rightarrow \infty$ as $t \rightarrow 0$ from above. Although our model breaks down at $t=0$, it is well behaved in the limit as $t \rightarrow 0$ from above. Therefore, we feel justified in ignoring the technical problems that arise at time 0 .
} 
two productive sectors in the steady-state equilibrium of the integrated economy. In the diagram, we depict the case in which R \& D is more human capital intensive than production of the differentiated products. In any event, the allocation at point $C^{\infty}$ can be decomposed into feasible allocations for the two countries provided that $a_{H x} / a_{L x}>$ $H_{a} / L_{a}>H_{b} / L_{b}>a_{H y} / a_{L y}$. In the figure, this decomposition is achieved by allocating in country $\mathrm{A}$ the vector of factors $A M^{\infty}$ to the production of modern goods and the vector $M^{\infty} E$ to the production of $y .^{13}$ Finally, consider allocations at times between $t=0$ and $t=\infty$. Points $C^{1}$ and $C^{2}$ represent sectoral allocations for the equilibrium of the integrated economy. Each such point can be viewed as an allocation of some factors to industry $y$ and some factors to the combined activity of development and production of modern goods. The latter composite activity requires factors in proportions intermediate to the requirements for the two component activities. It follows that if it is feasible to decompose the employment vectors of the integrated economy corresponding to the initial allocation and the steady-state allocation, then it will also be possible to do so for all times between these extremes. A sufficient condition for factor price equalization to obtain all along the path of the trade equilibrium is that the human capital to labor ratios of the two countries be bounded by the factor intensities of (i) the less human capital-intensive activity among R \& D and production of differentiated products and (ii) the production of good $y$. For the remainder of this section, we shall assume that this condition is satisfied.

At an arbitrary point in time, the full employment conditions for a single country can be represented with the help of (14)-(17) as

$$
L_{i}=a_{L y} Y_{i}+a_{L, x} \frac{s_{x} E}{n p} n_{i}+a_{L n} \dot{n}_{i}
$$

and

$$
H_{i}=a_{H y} Y_{i}+a_{H x} \frac{s_{x} E}{n p} n_{i}+a_{H n} \dot{n}_{i}
$$

for $i=a, b$. Combining these two equations and eliminating $Y_{i}$, we have

$$
\dot{n}_{i}+b(t) n_{i}=k_{i}
$$

${ }^{13}$ We must show further that this proposed allocation of resources to the production of industrial goods in each country is consistent with the number of products previously developed there since outputs of all varieties are equal in the integrated equilibrium. We establish below that this condition is indeed satisfied for the proposed decomposition. 
where

$$
\begin{aligned}
k_{i} & =\frac{L_{i}\left[\left(H_{i} / L_{i}\right)-\left(a_{H y} / a_{L y}\right)\right]}{a_{L, n}\left[\left(a_{H n} / a_{L n}\right)-\left(a_{H y} / a_{L y}\right)\right]}, \text { for } i=a, b, \\
b(t) & =\frac{a_{L, x}\left[\left(a_{H x} / a_{L, x}\right)-\left(a_{H y} / a_{L, y}\right)\right]}{a_{L, n}\left[\left(a_{H n} / a_{L, n}\right)-\left(a_{H y} / a_{L y}\right)\right]} \frac{s_{x} E(t)}{n(t) p(t)},
\end{aligned}
$$

and the functions $E(t), p(t)$, and $n(t)$ are taken from the integrated world equilibrium. This differential equation can be solved explicitly, which gives

$$
n_{i}(t)=k_{i} \int_{0}^{t} e^{-\int_{z}^{t} b(\tau) d \tau} d z .
$$

In writing $(21)$, we have set $n_{i}(0)=0$.

An important conclusion emerges from equation (21): the ratio of the numbers of differentiated goods produced in either country is constant for all $t$. We see that $n_{a}(t) / n_{b}(t)=k_{a} / k_{b}$. Then the ratio of $\mathrm{R} \&$ $\mathrm{D}$ activity in the two countries, $\dot{n}_{a} / \dot{n}_{b}$, is also constant and equal to $k_{a} / k_{b}$, as is the ratio of the total outputs of modern goods, $X_{a} / X_{b}{ }^{14}$

These features of the trade equilibrium can also be seen from figure 2. Recall that the points $M^{0}, M^{1}, M^{2}$, and $M^{\infty}$ represent allocations of factors in country A to the composite activity of R \& D and the production of differentiated goods in the two-country equilibrium. These points all lie on a straight line through $E$ with slope $a_{H y} / a_{L y}$. We can further decompose these allocations into vectors of factors employed in the component industries. For example, at time 1 (corresponding to global allocation $C^{1}$ ), country A employs the vector of factors $A P^{1}$ in $\mathrm{R} \& \mathrm{D}$ and the vector $P^{1} M^{1}$ in the production of differentiated products, while country B employs $M^{1} N^{1}$ in R \& D and $N^{1} C^{1}$ in producing modern goods. The corresponding points for time 2 are shown in figure 3 , where we have enlarged the relevant portion of figure 2. In figure 3 , the triangles $A P^{1} M^{1}$ and $M^{1} N^{1} C^{1}$ are similar triangles, as are the triangles $A P^{2} M^{2}$ and $M^{2} N^{2} C^{2}$. Thus, at each moment in time, the ratio of investments in $\mathrm{R} \& \mathrm{D}$ in the two countries equals the ratio of their total outputs of differentiated products. Finally, because $M^{1} M^{2}$ is parallel to $C^{1} C^{2}$, both of these ratios must remain constant through time.

We are now prepared to investigate the evolution of the pattern of trade. Consider first the direction of trade in traditional goods at some arbitrary time $t$. From equations (19) and (20) we can solve for

\footnotetext{
${ }^{14}$ We note that $x(t)$ is common to goods produced in both countries because factor price equalization implies equal prices of the different differentiated goods, and thus equal amounts of these goods are demanded by consumers. Since $X_{i}(t)=n_{i}(t) x(t)$, the last statement follows.
} 


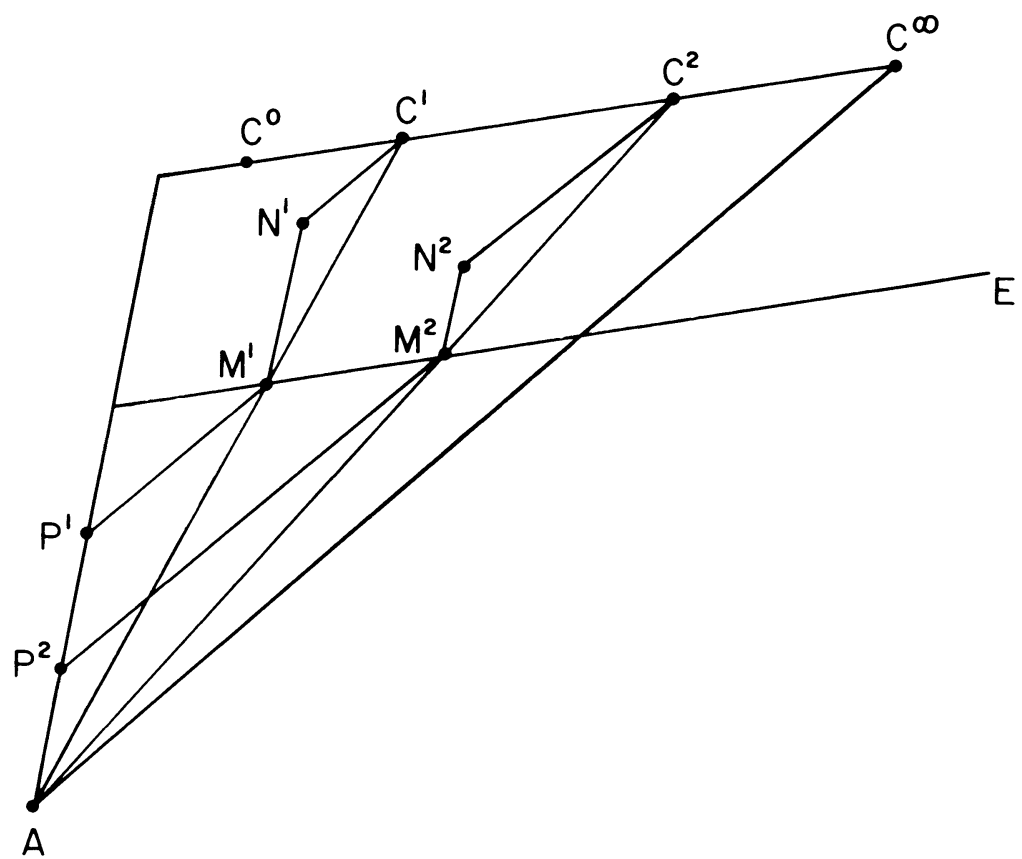

FIG. 3

the ratio of outputs, which is given by

$$
\frac{Y_{a}(t)}{Y_{b}(t)}=\frac{L_{a}\left[h_{c}(t)-\left(H_{a} / L_{a}\right)\right]}{L_{b}\left[h_{c}(t)-\left(H_{b} / L_{b}\right)\right]},
$$

where $h_{c}(t)$ is the human capital to labor ratio in the composite activity of R \& D and production of the modern goods. Since $h_{c}$ is a weighted average of the human capital intensities of the two component activities, it is bounded by $h_{n} \equiv a_{H n} / a_{I n}$ and $h_{x} \equiv a_{H x} / a_{I x x}$. But each of these exceeds $h_{i} \equiv H_{i} / L_{i}$ under the conditions needed for factor price equalization, so $h_{c}(t)-\left(H_{b} / L_{b}\right)>h_{c}(t)-\left(H_{a} / L_{a}\right)>0$. It follows that $Y_{a}(t) / Y_{b}(t)<L_{a} / L_{b}$.

Next we calculate the ratio of demands for the traditional good. In each country, expenditure on good $y$ is a constant fraction of total expenditure. Since consumers in both countries face the same price for the good, the ratio of aggregate demands is equal to the ratio of total expenditures. Now, from $(5), E_{i}(t)=E_{i}(0) e^{R(t)-\rho t}$, so $E_{a}(t) / E_{b}(t)=$ $E_{a}(0) / E_{b}(0)$. This ratio is, in turn, equal to the ratio of initial wealth levels, that is,

$$
\frac{E_{a}(0)}{E_{b}(0)}=\frac{L_{a}}{L_{b}} \frac{\int_{0}^{\infty} e^{-R(t)}\left[w(t)+r(t) h_{a}\right] d t}{\int_{0}^{\infty} e^{-R(t)}\left[w(t)+r(t) h_{b}\right] d t} .
$$


Note that the ratio of initial wealth levels on the right-hand side of (22) includes only factor incomes because initial asset holdings are zero and assets acquired along the path earn no excess returns.

Equation (22) and $h_{a} / h_{b}>1$ together imply $E_{a}(0) / E_{b}(0)>L_{a} / L_{b}$. Thus the ratio of demands for good $y, c_{y a}(t) / c_{y b}(t)$, also exceeds $L_{a} / L_{b}$. Since $Y_{a}(t) / Y_{b}(t)<L_{a} / L_{b}$, it follows immediately that $c_{y a}(t) / c_{y b}(t)>$ $Y_{a}(t) / Y_{b}(t)$. But $c_{y a}(t)+c_{y b}(t)=Y_{a}(t)+Y_{b}(t)$ by market clearing, implying $c_{y a}(t)>Y_{a}(t)$, as stated in the following proposition.

Proposition 2. The human capital-rich country imports the laborintensive, traditional good at every moment in time.

It is not surprising, of course, that factor endowments should play a major role in determining the direction of trade in traditional goods. What is surprising, perhaps, is that neither the diversion of resources to $\mathrm{R} \& \mathrm{D}$ nor the existence of aggregate trade imbalances can upset the strong prediction of the Heckscher-Ohlin theorem at any point along the equilibrium path.

We establish a similar result for trade in differentiated products. Each differentiated product is manufactured in only one country, yet each is consumed worldwide, so the direction of trade in the individual products is clear-cut. The existence of such intraindustry trade features prominently in the static models of trade with increasing returns to scale. We focus here on the aggregate pattern of trade for the sector as a whole. We have already shown that $X_{a} / X_{b}$ is constant over time. So too is $C_{x a} / C_{x b}$, where $C_{x i} \equiv n c_{x i}$. This ratio, like that for consumption of good $y$, equals the ratio of initial wealth levels in the two countries. Now if $C_{x a} / C_{x b}>X_{a} / X_{b}$, this would imply that country A imports both goods for all $t$. But such an outcome would violate the (aggregate) intertemporal budget constraint (4). We conclude, therefore, that $C_{x a} / C_{x b}<X_{a} / X_{b}$, as recorded in the following proposition.

Proposition 3. The human capital-rich country is a net exporter of differentiated products at every moment in time.

Next we consider the volume of trade, which is defined as the sum of exports across countries and industries. In our case, it is given by

$$
\mathbf{V} T=p_{y}\left(Y_{b}-s_{b} Y\right)+s_{a} p X_{b}+s_{b} p X_{a},
$$

where $s_{i}(i=a, b)$ is the share of country $i$ in spending, and $X_{i}=n_{i} x$ is country $i$ 's output of manufactures. Dividing by world spending and rearranging, we obtain

$$
\frac{\mathbf{V} T}{E}=\left(1-s_{x}\right)\left(\frac{Y_{b}}{Y}-s_{b}\right)+s_{x}\left(s_{a} \frac{X_{b}}{X}+s_{b} \frac{X_{a}}{X}\right),
$$

where $X$ and $Y$ are the aggregate output levels for the world economy. The second term on the right-hand side is constant on the dynamic trajectory. The first term changes as a result of shifts in country B's 
share of output of traditional goods. When $\mathrm{R} \& \mathrm{D}$ is human capital intensive relative to production of differentiated products, $Y_{b} / Y$ rises through time and the volume of trade rises faster than spending. In addition, because of declining investment, the ratio of world spending to world GNP increases over time. Hence, we have established the following proposition.

Proposition 4. If product development is human capital intensive relative to production of differentiated products, the volume of world trade grows faster than world spending and GNP.

Finally, we consider the pattern of intertemporal trade. Aggregate national savings (the difference between GNP and total expenditure) are used to accumulate foreign assets. We may think of these assets as ownership shares in firms, in which case current account imbalances give rise to foreign equity ownership. Or we may think instead that international trade takes place in short-term bonds, with all firms owned by local residents. The two forms of portfolio trade are equivalent here, as is clear from the fact that the profit rate equals the instantaneous interest rate (see [11]).

There are two offsetting influences at work in determining the current account. On the one hand, the human capital-rich country undertakes relatively more investment in product development than would be predicted on the basis of its relative size alone. This excess of investment demand tends to create a current account deficit for this country. On the other hand, the reward to human capital is falling over time, while the wage rate of unskilled workers is rising, so that the human capital-rich country experiences a decline in its relative factor income. This effect alone should lead country A to save a relatively greater share of its income, at least early on. For these reasons, it seems possible that the human capital-rich country may be running either a deficit or a surplus on its current account. We have not been able to establish any analytical results that prove otherwise.

\section{Multinational Corporations}

Our analysis to this point has maintained an assumption that every brand must be produced in the country in which it was originally developed. This requirement excludes the possibilities of international licensing and multinational investment. Naturally, under the conditions of the previous section, entrepreneurs have no incentive to license and firms have no incentive to become multinational. Suppose, however, that $\mathrm{R} \& \mathrm{D}$ requires more human capital per unskilled labor than production of industrial goods and that country A's human capital to unskilled labor ratio is larger than factor proportions observed in the industrial sector. In terms of figure 2, this means that 
point $E$ lies above the ray $A C^{\infty}$. Then the integrated equilibrium cannot be replicated by commodity trade without either licensing or the emergence of multinational corporations. In what follows we explore the latter possibility.

Following Helpman (1984), we assume that production of a variety comprises two distinct activities that can be decomposed, so that headquarter services can be located in one country while actual manufacturing takes place in another. For simplicity we assume that headquarter services are produced with human capital and that production plants use these services and unskilled labor only. ${ }^{15}$ Suppose also that headquarter services must be provided in the country in which a brand was developed. Then the integrated equilibrium can be reproduced even when the endowment point $E$ is above $A C^{\infty}$ in figure 2 . The resulting allocation patterns are shown in figure 4 for the case in which the extent of multinationality is minimal (see Helpman [1984] for a discussion of this assumption).

It is clear from the figure that up to time $T_{m}$, at which $C^{T_{m}}$ represents resource allocation in the integrated equilibrium, there is no pressure for the formation of multinational corporations. However, immediately after this point in time, equality of factor rewards cannot be maintained if both activities of industrial firms are concentrated in the same country. This exerts pressure for their separation, with the tendency to locate manufacturing operations in the potentially unskilled labor-cheap country (i.e., country B). At time $T$ the allocation of the

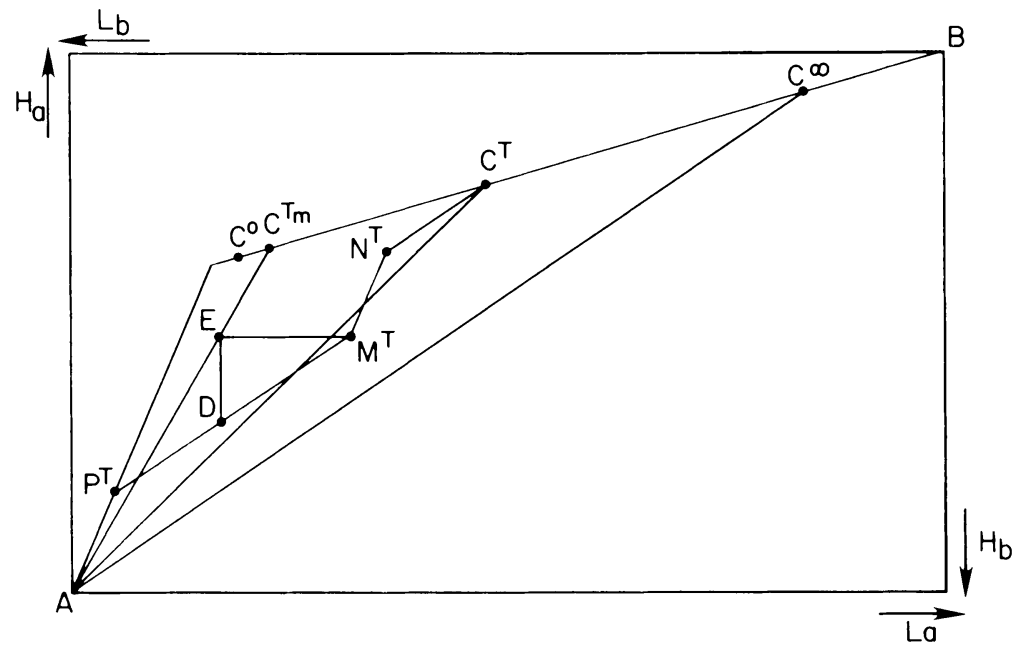

FIG. 4

${ }^{15}$ It is easy to see how the analysis is modified when both activities require human capital and unskilled labor, as in Helpman and Krugman (1985, chap. 12). 
integrated equilibrium is described by point $C^{T}$ in the figure. Its aggregate variables are reproduced by the following allocation in the trade equilibrium. Country A does not produce the traditional good. It devotes resources $A P^{T}$ to $\mathrm{R} \& \mathrm{D}, P^{T} D$ to production of industrial products by firms that are not multinational, and $D E$ to the production of headquarter services by its multinationals. Country B devotes resources $B C^{T}$ to the production of $y$-goods, $C^{T} N^{T}$ to the production of industrial products by domestic firms (which are not multinational), $N^{T} M^{T}$ to $\mathrm{R} \& \mathrm{D}$, and $M^{T} E$ to production of modern goods in plants owned by country A's multinational corporations.

It is clear from this description that, starting with $t=T_{m}$, the extent of multinationality-as measured by employment in subsidiaries or their output volume-is increasing at least initially; we have not been able to prove that it is increasing throughout. We can show, however, that the extent of multinationality also increases during the final approach to the steady state. The latter point is seen as follows. The condition of minimal foreign involvement implies that from time $T_{m}$, country A does not produce the traditional good. Therefore, after that point in time, its factor market-clearing conditions read as (compare with the discussion of fig. 4)

$$
\begin{gathered}
a_{L n} \dot{n}_{a}+a_{L x}\left(n_{a}-m\right) x=L_{a}, \\
a_{H n} \dot{n}_{a}+a_{H x} n_{a} x=H_{a},
\end{gathered}
$$

where $m$ is the number of products produced in foreign subsidiaries and $x$ is output per firm, taken from the integrated world equilibrium.

From (25) we observe that output of modern products is increasing in country $A$ if and only if $R \& D$ is declining. Since $R \& D$ approaches zero when the steady state is approached, $n_{a} x$ must be increasing close to the steady state. However, from (24) and (25) we obtain

$$
m x=\frac{L_{a}}{a_{L x} h_{n}}\left(h_{a}-h_{n}\right)+\frac{1}{h_{n}}\left(h_{n}-h_{x}\right) n_{a} x,
$$

which together with the previous result implies that the degree of multinationality increases close to the steady state (recall that $h_{n}>h_{x}$ is assumed in this section).

We have shown that the degree of multinationality-as measured by the volume of output or employment in subsidiaries-is increasing when the multinationals start to form and when the economy approaches a steady state. These results can be extended to cover a third definition of the extent of multinationality: the number of varieties produced by subsidiaries. This number obviously is rising initially, when the multinationals start to form. That it is also rising close to the steady state we show by proving that $x$ is declining close to the steady 
state. Since we have already shown that $m x$ is rising, a declining $x$ implies a rising $m$, that is, an increasing number of varieties produced by subsidiaries.

The proof proceeds as follows. Since the dashed path in figure 1 is above the $\dot{E}=0$ line, the ratio $E / n$ is declining when the trajectory approaches point $(\bar{n}, \bar{E})$. On the other hand, from part $d$ of proposition 1 we know that $p$ is increasing as this point is approached because in this section we require $\mathrm{R} \& \mathrm{D}$ to be more human capital intensive than $x$. Therefore, $x=s_{x} E / p n$ is declining close to the steady state. Hence, we have the following proposition.

Proposition 5. If differences in factor composition are wide enough and product development is human capital intensive relative to production of differentiated products, then there exists a time at which multinational corporations emerge. The degree of multinationality-as measured by the number of products produced by subsidiaries, their volume of output, or employment-is rising initially and when the world economy approaches the steady state.

In closing this section we note that the pattern of trade described in the previous section need not hold in the presence of multinationals. It is clear that the direction of trade in traditional goods must be the same as before. However, the pattern of trade in modern goods might change over time. Country A, which begins as a net exporter of differentiated products prior to the emergence of multinationals, may evolve into a net importer of these goods if it ultimately exports a sufficient quantity of headquarter services.

\section{Concluding Remarks}

We have extended a number of important results in international trade theory to a dynamic environment in which comparative advantage must be developed over time via the allocation of resources to research and development. In our specification, $\mathrm{R} \& \mathrm{D}$ must take place prior to the production of any new variety of a differentiated product. This $\mathrm{R} \& \mathrm{D}$ is motivated by the stream of profits that accrues to the producer of a differentiated good and is financed by savings that are endogenously determined. When $\mathrm{R} \& \mathrm{D}$, production of differentiated products, and production of a homogeneous good all require fixed input proportions of two primary factors, then the Heckscher-Ohlin pattern of trade is preserved all along the dynamic path of the trading equilibrium. This is true despite the fact that trade is not balanced along this path. We also established that if product development is human capital intensive relative to production of differentiated products, the volume of trade as a fraction of world GNP or world expenditure grows over time. Finally, for certain factor endow- 
ments, we have predicted the emergence of multinational corporations and shown that in these circumstances the extent of multinational activity generally rises over time.

The framework that we have developed here is suitable for the study of additional issues. Our analysis has excluded factor accumulation and has restricted attention to horizontal product differentiation. We plan in future work to consider the interaction between capital investment and technological progress in determining trade dynamics and to study the evolution of trade patterns with vertically differentiated goods and hence endogenous product obsolescence. Perhaps more fundamentally, after slight adaptation of our framework, it becomes possible to study the links between the trade environment (including policy) and long-run rates of growth. We present our initial efforts to understand the relationship between aspects of the international economy and long-run economic performance when product innovation drives growth in Grossman and Helpman (1988).

\section{Appendix}

We provide in this Appendix a proof of proposition 1 by explicitly calculating expressions for the comovement of six variables with expenditure $E$. By substituting (16) and (17) into (14) and using the result together with (7), (10), and (12) for the special case considered in Section IID-namely, two factors of production and constant coefficients-we obtain the following system:

$$
\begin{gathered}
1=a_{L n} w+a_{H n} r, \\
\alpha p=a_{L, x} w+a_{H x} r, \\
p_{y}=a_{L, y} w+a_{H y} r, \\
L=a_{L n} \dot{n}+a_{L, x} s_{x} \frac{E}{p}+a_{L, y}\left(1-s_{x}\right) \frac{E}{p_{y}}, \\
H=a_{H n} \dot{n}+a_{H x} s_{x} \frac{E}{p}+a_{H y}\left(1-s_{x}\right) \frac{E}{p_{y}},
\end{gathered}
$$

where $w$ is the reward to unskilled labor and $r$ is the reward to human capital. This system enables us to solve $\left(w, r, p, p_{y}, \dot{n}\right)$ as functions of $E$. In what follows, we calculate the proportional rate of change of each one of these variables in response to a proportional change in expenditure of $\hat{E} \equiv d E / E=1$; a circumflex over a variable indicates a proportional rate of change. The following expressions use the standard notation; that is, $\theta_{i j}$ is the share of input $i$ in the cost of activity $j$ and $\lambda_{i j}$ is the share of factor $i$ employed in activity $j$ :

$$
\begin{gathered}
\hat{w}=\frac{1}{\Delta} \theta_{H n}\left(\lambda_{H n}-\lambda_{L n}\right), \\
\hat{r}=\frac{1}{\Delta} \theta_{L n}\left(\lambda_{L n}-\lambda_{H n}\right), \\
\hat{p}=\frac{1}{\Delta}\left(\theta_{L, x}-\theta_{L n}\right)\left(\lambda_{H n}-\lambda_{L n}\right),
\end{gathered}
$$




$$
\begin{gathered}
\hat{p}_{y}=\frac{1}{\Delta}\left(\theta_{L y}-\theta_{L n}\right)\left(\lambda_{H n}-\lambda_{L n}\right), \\
\hat{\dot{n}}=\frac{1}{\Delta}\left(\theta_{L y}-\theta_{L x}\right)\left(\lambda_{L x} \lambda_{H y}-\lambda_{L y} \lambda_{H x}\right),
\end{gathered}
$$

where

$$
\begin{aligned}
\Delta= & \left(\theta_{L x}-\theta_{L n}\right)\left(\lambda_{L x} \lambda_{H n}-\lambda_{L n} \lambda_{H x}\right) \\
& +\left(\theta_{L y}-\theta_{L n}\right)\left(\lambda_{L y} \lambda_{H n}-\lambda_{L n} \lambda_{H y}\right) .
\end{aligned}
$$

From the definition of $\Delta$, we have $\Delta>0$ because $\left(\theta_{L i}-\theta_{L j}\right)$ is of the same sign as $\left(\lambda_{L i} \lambda_{H j}-\lambda_{L j} \lambda_{H i}\right)$, being positive when $i$ is labor intensive relative to $j$ and negative when $i$ is human capital intensive relative to $j$. We have assumed that $a_{H y} / a_{L y}<H / L<a_{H i} / a_{L i}, i=x, n$, which implies

$$
\begin{gathered}
\lambda_{H y}-\lambda_{L y}<0, \\
\lambda_{H i}-\lambda_{L i}>0 \text { for } i=x, n .
\end{gathered}
$$

Condition (A12b) proves parts $b$ and $c$ of proposition 1, given part $h$, which is proved in the text. From (A6) and (A9), we obtain

$$
\hat{w}-\hat{p}_{y}=\frac{1}{\Delta} \theta_{H y}\left(\lambda_{H n}-\lambda_{L n}\right)
$$

from (A8) and (A9), we obtain

$$
\hat{p}_{y}-\hat{p}=\frac{1}{\Delta}\left(\theta_{L y}-\theta_{L x}\right)\left(\lambda_{H n}-\lambda_{L n}\right) ;
$$

and from (A7) and (A8), we obtain

$$
\hat{p}-\hat{r}=\frac{1}{\Delta} \theta_{L x}\left(\lambda_{H n}-\lambda_{L n}\right) .
$$

Equations (A13)-(A15) together with (A12b), part $h$, and the assumption that $y$ is labor intensive relative to $x$ - which implies $\theta_{L y}>\theta_{L x}$-prove part $a$ of the proposition. Part $d$ is a direct consequence of part $h$, (A8), and (A12b). Part $e$ is a direct consequence of (A 10) and part $h$. Moreover, (A10) proves that the function $v(E)$ is declining because the right-hand side of (A10) is negative.

From (16) and (17) we have $\hat{X}=\hat{E}-\hat{p}$ and $\hat{Y}=\hat{E}-\hat{p}_{y}$. Using these expressions, $\hat{E}=1$, as well as (A8), (A9), and (A11), we obtain

$$
\hat{X}=\frac{1}{\Delta}\left(\theta_{L y}-\theta_{L x}\right)\left(\lambda_{L y} \lambda_{H n}-\lambda_{L n} \lambda_{H y}\right)
$$

and

$$
\hat{Y}=\frac{1}{\Delta}\left(\theta_{L y}-\theta_{L x}\right)\left(\lambda_{L n} \lambda_{H x}-\lambda_{L x} \lambda_{H n}\right) .
$$

Equations (A12a) and (A12b) together with the assumption that $y$ is labor intensive relative to $x$ imply that the right-hand side of (A16) is positive. This together with part $h$ proves part $f$ of the proposition. From (A17), it is evident that, given that $y$ is labor intensive relative to $x$, the right-hand side is positive if and only if $n$ is labor intensive relative to $x$, which together with part $h$ proves part $g$. 


\section{References}

Dixit, Avinash, and Norman, Victor D. Theory of International Trade: A Dual, General Equilibrium Approach. Cambridge: Cambridge Univ. Press, 1980.

$\rightarrow$ Dollar, David. "Technological Innovation, Capital Mobility, and the Product Cycle in the North-South Trade." A.E.R. 76 (March 1986): 177-90.

$\rightarrow$ Feenstra, Robert C., and Judd, Kenneth L. "Tariffs, Technology Transfer, and Welfare." J.P.E. 90 (December 1982): 1142-65.

Grossman, Gene M., and Helpman, Elhanan. "Comparative Advantage and Long-Run Growth." Discussion Paper in Economics no. 142. Princeton, N.J.: Princeton Univ., Woodrow Wilson School, 1988.

$\rightarrow$ Helpman, Elhanan. "A Simple Theory of International Trade with Multinational Corporations.” J.P.E. 92 (June 1984): 451-71.

Helpman, Elhanan, and Krugman, Paul R. Market Structure and Foreign Trade: Increasing Returns, Imperfect Competition, and the International Economy. Cambridge, Mass.: MIT Press, 1985.

Jensen, Richard, and Thursby, Marie. "A Decision Theoretical Model of Innovation, Technology Transfer, and Trade." Rev. Econ. Studies 54 (October 1987): $631-47$.

Judd, Kenneth L. "On the Performance of Patents." Econometrica 53 (May 1985): 567-85.

$\rightarrow$ Krugman, Paul R. "Increasing Returns, Monopolistic Competition, and International Trade." J. Internat. Econ. 9 (November 1979): 469-79. (a)

$\longrightarrow \rightarrow$ - "A Model of Innovation, Technology Transfer, and the World Distribution of Income." J.P.E. 87 (April 1979): 253-66. (b)

$\rightarrow-$. "Intraindustry Specialization and the Gains from Trade." J.P.E. 89 (October 1981): 959-73.

Segerstrom, Paul S.; Anant, T. C. A.; and Dinopoulos, Elias. "A Schumpeterian Model of the Product Life Cycle." Econometrics and Economic Theory Paper no. 8606. East Lansing: Michigan State Univ., 1987. 